\title{
Comparación entre técnicas bilaminares y regenerativas para recubrir las raíces
}

\author{
CAVENAGHI, G*. \\ CACCIANIGA, GL*. \\ BALDONI, $\mathbf{M} * *$. \\ LAMEDICA, M***.
}

\author{
Cavenaghi, G; Caccianiga, GL; Baldoni, M; Lamedica, M. Comparación \\ entre técnicas bilaminares y regenerativas para recubrir las raíces. \\ Av Periodon Implantol. 2000; 12, 127-136
}

\begin{abstract}
RESUMEN
El objetivo de este artículo en relación con los estudios publicados en la literatura internacional consiste en comparar las posibilidades terapéuticas que ofrecen las técnicas bilaminares y las de regeneración hística guiada (RHG) para recubrir las superficies radiculares expuestas a causa de las recesiones gingivales.
\end{abstract}

La experimentación se ha realizado con 20 pacientes, 13 hombres y 7 mujeres, con edades de 25/39 años. Se dividió a los pacientes en dos grupos, A y B, según las técnicas quirúrgicas, bilaminar y regenerativa, respectivamente. Los sujetos con recesiones múltiples y adyacentes se asignaron al grupo $A$.

\begin{abstract}
Al considerar los datos de este estudio clínico, coincidentes con los de la literatura internacional, se puede afirmar que el injerto de tejido conectivo es una alternativa válida para la RHG en el tratamiento de las recesiones gingivales. De hecho, las técnicas bilaminares permiten aumentar la cantidad y el espesor de la encía insertada, tratar varias recesiones adyacentes y garantizar una gran predicibilidad en recubrimiento radicular.
\end{abstract}

\section{PALABRAS CLAVE}

Recesiones gingivales, encía insertada, injerto bilaminar/RHG.

El objetivo de este artículo en relación con los estudios publicados en la literatura internacional consiste en comparar las posibilidades terapéuticas que ofrecen las técnicas bilaminares y las de regeneración hística guiada (RHG) para recubrir las superficies radiculares expuestas a causa de las recesiones gingivales.

\section{RECESIONES GINGIVALES}

Las recesiones gingivales son una patología frecuente (fig. 1).
Se considera que una recesión gingival es la exposición de la superficie radicular de uno o de muchos dientes causada por la migración de la encía marginal y del epitelio de inserción a un nivel más apical. Consecuentemente, esta definición implica el concepto de exposición radicular, con pérdida del tejido periodontal marginal de gravedad variable, que constituye un hallazgo clínico permanente en las recesiones gingivales.

En la actualidad, las recesiones gingivales representan una patología muy importante para los pacientes, sobre todo en dos tipos de problemas: por un lado la estética, en especial cuando se afectan los dientes frontales y la hipersensibilidad dentinaria, importan-

* Università degli Studi di Milano. Istituto di Discipline Odontostomatologiche. Direttore: Prof. G. Calderari.

** Ricercatore confermato, titolare per affidamento Parodontologia. Ospedale San Raffaele.

*** Libero Professionista. 


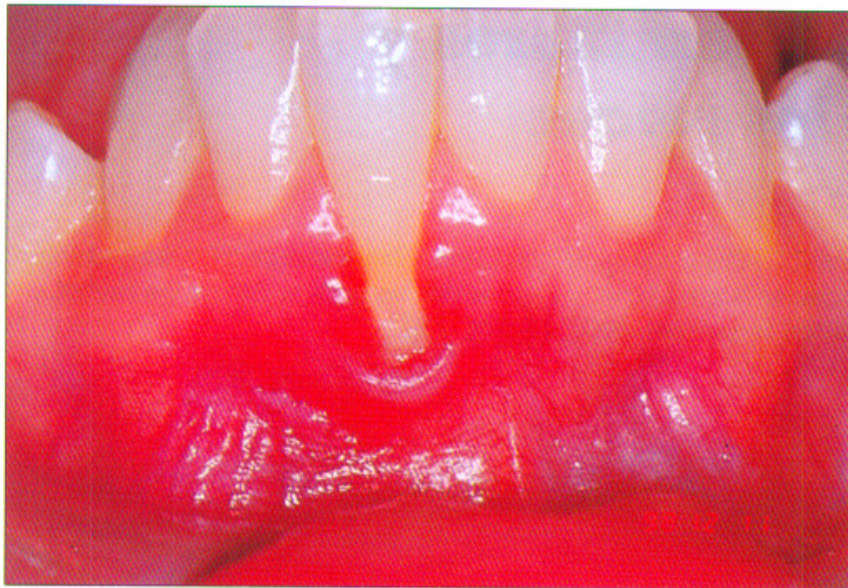

Fig. 1: Recesión gingival en 41. La recesión sobrepasa la línea mucogingival.

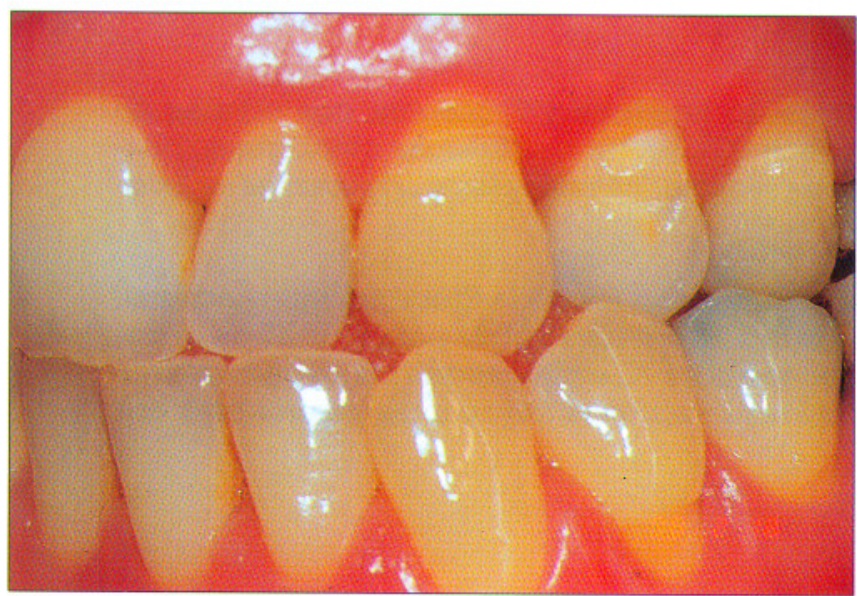

Fig. 2: Recesiones gingivales múltiples en un paciente con total inversión del lado izquierdo.

te debido al creciente déficit funcional, y por otro lado la dificultad para llevar a cabo una correcta higiene oral. ${ }^{1,3,5,24}$

\section{FACTORES ETIOLÓGICOS}

En la etiología de las recesiones gingivales existen factores determinantes y predisponentes.

Entre los determinantes, los más frecuentes son la acción traumática del cepillado, la placa microbiana, los hábitos y el trauma oclusal. Por desgracia, las causas yatrogénicas de la recesión son frecuentes: restauraciones sobrecontorneadas, sobre todo en clase 5 , brackets ortodóncicos incorrectamente posicionados, cirugía gingival, restauraciones protésicas incongruentes, etc. (figs. 2-3).

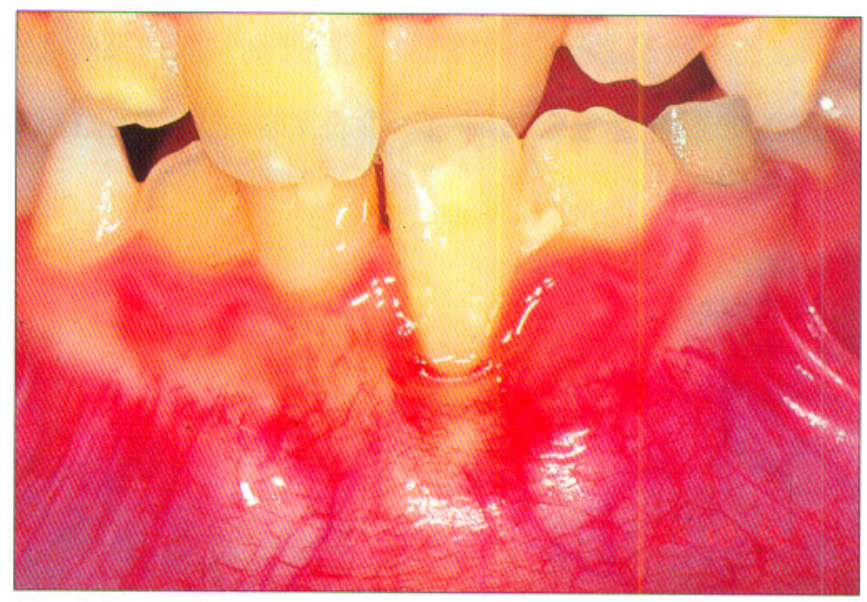

Fig. 3: Recesión gingival en 41, con placa bacteriana y trauma oclusal.

Entre los factores predisponentes destacan las anomalías anatómicas, como malposiciones dentales, frenillos altos e inserciones musculares, formics poco profundos y dehiscencias óseas.

$\mathrm{El}$ término dehiscencia se refiere a un trastorno en el que la superficie bucal, y con menor frecuencia la superficie lingual de la raíz de un diente, carece de la totalidad o de parte de su hueso de recubrimiento. Las dehiscencias pueden producirse inmediatamente después de la erupción como consecuencia de la posición del diente prominente en relación con el área dental, o bien desarrollarse posteriormente en las áreas en las que la superficie vestibular del hueso alveolar es más delgada. $1,3,3,8,11,12,18,19$

\section{IMPORTANCIA DE LA ENCÍA INSERTADA}

La encía insertada proporciona un epitelio queratinizado que, conjuntamente con su tejido conectivo subyacente, separa el margen libre gingival de la mucosa alveolar móvil. Sin esta barrera, los músculos de la expresión y la movilidad del labio y de la mejilla pueden causar un movimiento o una eversión del margen gingival libre, con la consiguiente acumulación de placa y mayor infiltración microbiana en el surco crevicular.

Si se considera la diferencia histológica entre la encía insertada y la mucosa alveolar, es evidente que la primera es rica en colágeno y relativamente poco vascularizada. La progresión del proceso inflamatorio es perivascular, de modo que un tejido menos vascularizado y más fibroso proporciona mayor protección a la integridad de la encía.El aumento de encía insertada 
asegura una mejor barrera frente a la difusión del proceso inflamatorio previniendo la migración apical del epitelio de unión.

Con anterioridad a la década de 1960, se aceptaba la necesidad de un adecuado ancho de encía insertada para mantener un periodonto sano: $2 \mathrm{~mm}$ de tejido queratinizado con al menos $1 \mathrm{~mm}$ de encía insertada era la cantidad mínima aceptable.

Wennstrom ${ }^{28}$ (1987) demostró que la falta de encía insertada o la presencia de mínimas cantidades de la misma no produce necesariamente recesión gingival; de hecho, con las adecuadas medidas de control de la placa, el ancho apicocoronal de la encía insertada no es significativo para mantener un periodonto sano. En ese mismo estudio, la aparición de recesiones asociada con la disminución del ancho de la encía apoya la hipótesis de que una zona estrecha de encía apical a la recesión es la consecuencia más que la causa del desarrollo de la lesión.

Por tanto, la adecuación de la encía insertada debe estimarse más en función de su capacidad para observar el estrés al que está expuesta, que por los milímetros mínimos aceptables. , $2,4,10,13,17,28^{-1}$

\section{PATOGÉNESIS}

El mecanismo patogénico de las recesiones gingivales está relacionado con la interrupción de la integridad del epitelio. Como consecuencia, el problema inflamatorio destruye el tejido conectivo subyacente, en tanto que el epitelio migra a lo largo de los márgenes de la lesión en el tejido conectivo. El posterior desarrollo de la lesión da lugar a la interrupción del tejido conectivo y a la consiguiente unión del epitelio oral con el epitelio del surco de unión.

El aspecto clínico inicial es una ligera úlcera, con márgenes enrojecidos y que duelen al cepillado. Cuanto mayor sea la infiltración microbiana, mayor y más profunda será la lesión. ${ }^{3}$

\section{INDICACIONESY CONTRAINDICACIONES DEL TRATAMIENTO QUIRÚRGICO}

\section{Indicaciones:}

Actualmente, la mera presencia de una recesión gingival no se considera como una situación que requiera necesariamente cirugía: hay que valorar diferentes parámetros para considerarla necesaria.

Antes de planear cualquier acción terapéutica, es necesario corregir los factores que probablemente hayan causado la patología. Ello se consigue fácilmente instaurando un control de placa adecuado, eliminando cualquier factor traumático y cambiando el tratamiento conservador o las prótesis responsables de las lesiones yatrogénicas.

La persistencia de sensibilidad dentinaria no tratable de forma conservadora, la existencia de un problema estético, sobre todo cuando las lesiones se localizan en el sector frontal, y la presencia de caries en la raíz expuesta, son todas ellas indicaciones para el tratamiento quirúrgico. Junto con la valoración de las necesidades del paciente antes de la cirugía, hay que considerar su edad, el aumento de la recesión, su estabilidad o desarrollo, la presencia de encía insertada y por último la posibilidad de llevar a cabo otros procedimientos en el mismo diente. Si la recesión es estable, sin sensibilidad dentinaria o problemas estéticos, y si el paciente mantiene una higiene oral correcta, no existe indicación quirúrgica. Por el contrario si la recesión es progresiva, con una retención de placa anormal, o si es necesario realizar tratamientos protésicos u ortodóncicos, la cirugía puede estar indicada.

Assí pues, es fácil entender que si existe la necesidad de elegir entre aplicar o no técnicas quirúrgicas, la evaluación debe ser más profunda que la mera comprobación de la presencia de una recesión. .,27,28 $^{5,20}$

\section{Contraindicaciones:}

El nivel de higiene oral insuficiente y el tabaco se consideran contraindicaciones para la cirugía mucogingival.

Higiene oral: se acepta que un escaso nivel de higiene oral, así como la motivación del paciente, pueden comprometer irremediablemente el resultado terapéutico.

Tabaco: el tabaco ejerce una influencia negativa en la cicatrización del tejido oral en general y de las estructuras periodontales en particular. Miller ${ }^{14,15}$ (1987, 1993) demostró que el exceso de tabaco (más de 10 cigarrillos al día) se correlaciona estrechamente con el fallo en el cubrimiento radicular porque el tabaco altera la circulación hística y produce vasoconstricción que reduce el aporte sanguíneo. Los fumadores ocasionales o moderados 
(menos de 5 cigarrillos al día) muestran los mismos niveles de salud que los no fumadores. En contraste con la demostración de Miller, en otros estudios clínicos (Tolmie ${ }^{26}$ 1991, Harris ${ }^{7}$ 1994) no ha publicado ningún efecto significativo del tabaco sobre la cicatrización hística tras la cirugía mucogingival.

Edad: la literatura no imputa a la edad del paciente influencias negativas en el éxito del tratamiento quirúrgico. ${ }^{7,14,15,26,29,30}$

\section{ESTUDIO EXPERIMENTAL}

El objetivo de este estudio consiste en evaluar las posibilidades que ofrecen las técnicas bilaminares y por las técnicas de RHG para tratar quirúrgicamente las superficies radiculares expuestas a causa de las recesiones gingivales, en relación con los estudios publicados en la literatura internacional.

En lo referente al estudio de la literatura internacional, hay que señalar los artículos de la escuela suiza, sobre todo los de Wennstrom, relativos a la comparación de técnicas bilaminares y regenerativas.

Wennstrom ${ }^{30}$ comparó los resultados de los estudios clínicos más significativos en las diferentes técnicas quirúrgicas para el recubrimiento de las raíces expuestas, con especial atención a las técnicas bilaminares y regenerativas.

Los datos confirman que las técnicas bilaminares permiten un porcentaje medio de cubrimiento radicular del $89,3 \%$ con una recesión inicial de $3,8 \mathrm{~mm}$ de profundidad, en tanto que las técnicas regenerativas consiguen un porcentaje del $74,1 \%$ con una recesión inicial media de $5,3 \mathrm{~mm}$.

Otros autores ${ }^{31}$ han comunicado valores de cubrimiento radicular de 5,3 $\mathrm{mm}$ para los injertos bilaminares de tejido conectivo y de $4,9 \mathrm{~mm}$ para las técnicas de RHG, y han llegado a la conclusión de que las técnicas bilaminares pueden ser consideradas como una alternativa válida a la RHG para tratar la recesión gingival profunda superior a $4 \mathrm{~mm}$, y que la profundidad de la recesión no es necesariamente el parámetro para elegir el procedimiento quirúrgico.

\section{MATERIAL Y MÉTODOS}

El experimento se llevó a cabo con 20 pacientes, 13 hombres y 7 mujeres, de 25 a 39 años. Todos eran no fumadores, sanos y no tomaron antibióticos en los 6 meses anteriores.

Los pacientes tenían un delgado y festoneado biotipo periodontal, con dientes en forma afilada, áreas de contacto interproximales pequeñas, márgenes gingivales delgados y escaso tejido periodontal. Por tanto, los factores etiopatogénicos de estos pacientes ya les hacían susceptibles a desarrollar recesiones gingivales.

Se dividió a los pacientes en dos grupos, A y B, en función de las técnicas quirúrgica bilaminar y regenerativa, respectivamente. Los pacientes que presentaban recesiones múltiples y adyacentes se asignaron al grupo $\mathrm{A}$.

GRUPO A: Los 10 sujetos, 6 hombres y 4 mujeres, con un número total de 15 recesiones, fueron tratados con técnicas bilaminares: 6 injertos de tejido conectivo con colgajos posicionados coronalmente, 2 injertos de tejido conectivo con colgajos de doble papila y 2 técnicas de sobre (Raetzke 1985).

GRUPO B: Los 10 sujetos, 7 hombres y 3 mujeres, con un número total de 12 recesiones, fueron tratados con técnicas de RHG mediante membranas reabsorbibles (colágenos y glucosaminoglucanos), con hidroxiapatita como mantenedor de espacio.

\section{MÉTODO DEL ESTUDIO}

En la fase preoperatoria, el siguiente protocolo se aplicó a ambos grupos:

Preparación inicial - Se impartieron instrucciones rigurosas a todos los pacientes para que mantuvieran una higiene oral regular, adecuada y duradera. Esta fase se completó con sesiones de tartrectomía, aplanamiento radicular y eliminación de los factores etiológicos identificados como causantes o predisponentes del desarrollo de la lesión (higiene oral insuficiente, empleo de cepillos duros, restauraciones sobrecontorneadas, trauma oclusal, hábitos viciados).

$>$ Revaluación a los 60 días - A los dos meses, se observó una clara mejora de la higiene oral, con desaparición de las inflamaciones marginales; la gravedad de las lesiones tuvo una mejora máxima de $1 \mathrm{~mm}$.

Técnicas quirúrgicas - A todos los pacientes 
seleccionados se les practicó cirugía mucogingival en base a la división en dos grupos. Durante las intervenciones, todas las superficies expuestas fueron acondicionadas con una solución de tetraciclina (125 mg de tetraciclina/ml de solución salina estéril). 6 La superficie radicular se trató aplicando la solución de tetraciclina con pequeñas bolas de algodón sobre la superficie radicular, y con una fuerza comparable a la aplicada con la cureta para el aplanamiento radicular. La bola de algodón se cambió dos o tres veces cada minuto, cada 20 ○ 30 segundos para evitar contaminaciones. Cada raíz se trató durante al menos 3 minutos y después se lavó con agua abundante.

\section{Técnica quirúrgica: GRUPO A}

A los pacientes del grupo A, se les colocó sobre la superficie de la raíz expuesta un injerto de tejido conectivo tomado de la mucosa palatina, que se cubrió con un colgajo pediculado. La base biológica para esta técnica es que el colgajo destinado al cubrimiento radicular, y por tanto en contacto con la superficie avascular del diente, reciba doble vascularización desde el periostio subyacente y del colgajo pediculado colocado sobre el injerto. ${ }^{9}$

Las técnicas quirúrgicas se seleccionaron en función del número de recesiones, sobre todo si estaban juntas, y según la cantidad y calidad de los tejidos periodontales, con atención especial a la cantidad de encía insertada apicalmente a la recesión y al ancho y espesor de la papila interdental adyacente.

Los injertos de tejido conectivo se extrajeron del paladar con una técnica en dos pasos: se tomó un injerto conectivo epitelial de la zona donante, con dimensiones relacionadas con la extensión y el número de las superficies radiculares expuestas. El epitelio se eliminó cuidadosamente del injerto palatino con una hoja quirúrgica. La cicatrización de la zona donante fue por segunda intención.

Al final de la operación, se colocó un apósito quirúrgico en la zona donante y en la receptora.

En uno de los pacientes, el injerto de tejido conectivo se tomó del paladar con la técnica en trampilla, como la describieron Langer y Langer (1985). ${ }^{9}$ Esta técnica tiene la ventaja de permitir una cicatrización por primera intención de la zona donante, con menos molestias postoperatorias para el paciente (fig. 4-11).

Como recomendación para los primeros días posquirúrgicos, los pacientes fueron invitados a no cepillarse el área quirúrgica y a utilizar clorexidina $0,2 \%$ en enjuagues diarios para la higiene oral.

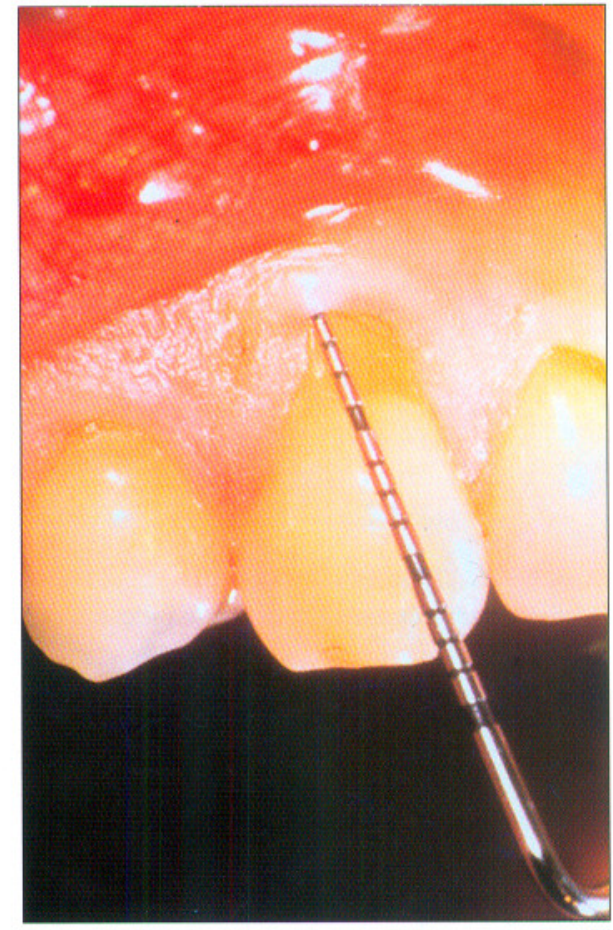

Fig. 4: Sondaje de la recesión gingival en 23 (paciente número 10 del grupo $A$ )

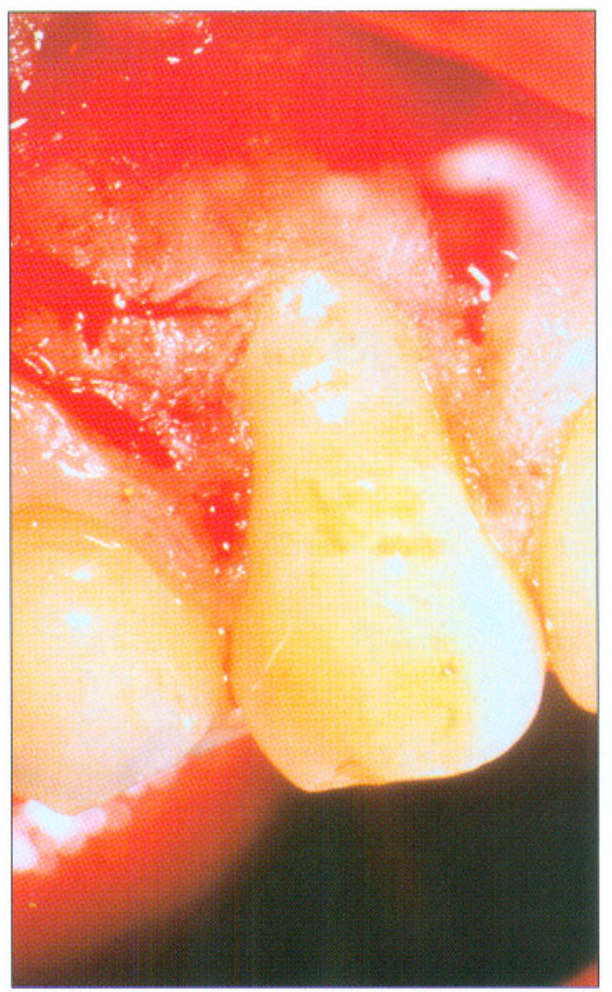

Fig. 5: Colgajo posicionado coronalmente: obsérvese el ancho del defecto óseo. 


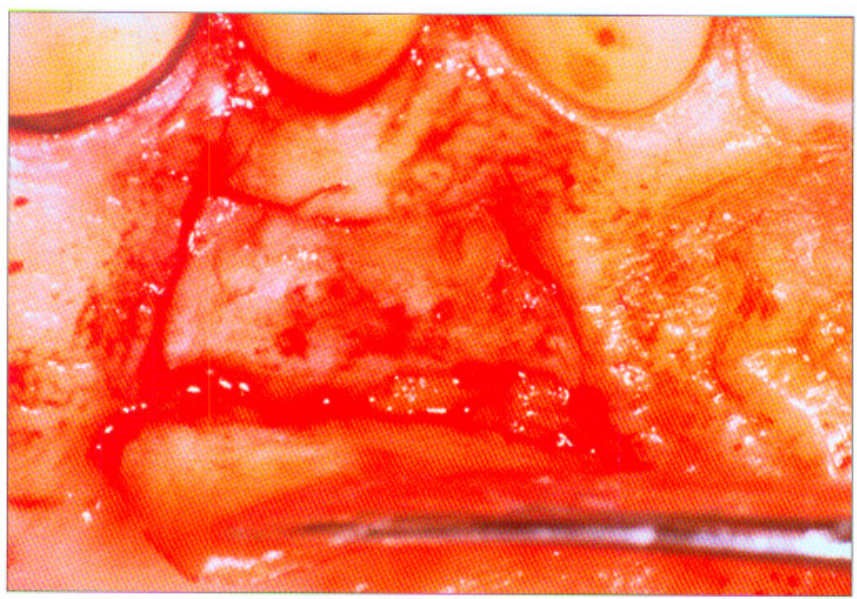

Fig. 6: Técnica en trampilla en el paladar: tallado del colgajo epitelial.

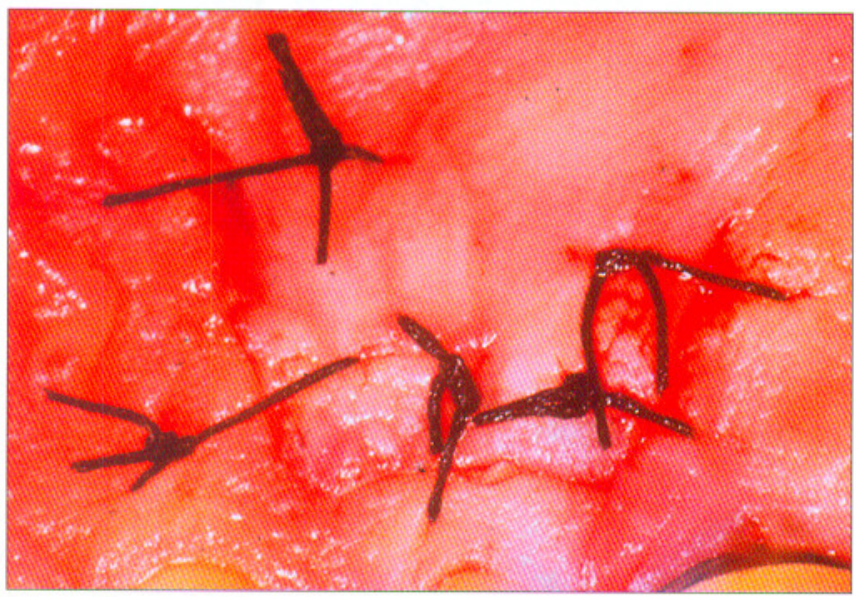

Fig. 7: Sutura del área palatina.

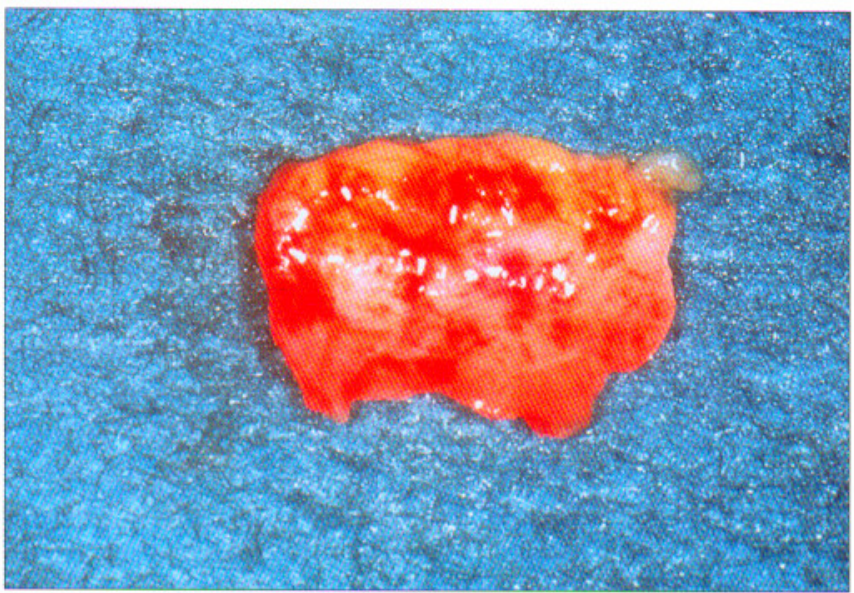

Fig. 8: Tejido conectivo. Toma.

Diez días después de la operación, se eliminaron los apósitos y suturas, aplicando gel de clorexidina en el área injertada bilaminar.

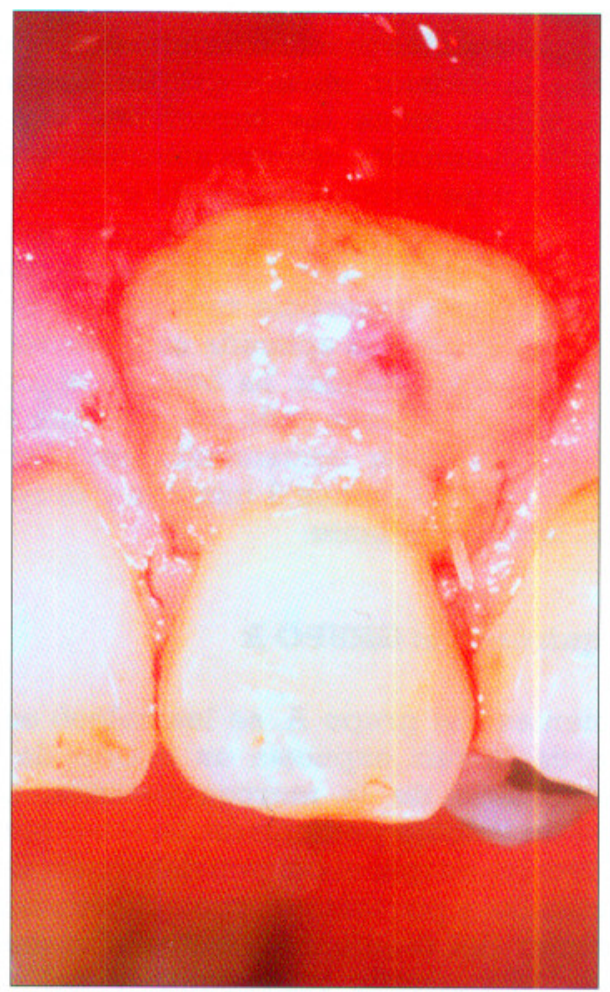

Fig. 9: Posicionamiento y sutura del injerto conectivo.

Los siguientes controles se realizaron a los 20 y 30 días. Después de ese período, los pacientes reanudaron sus medidas de control de placa, cepillando delicadamente el área tratada y siendo instruidos sobre la importancia de mantener permanentemente los elevados niveles de higiene oral alcanzados durante las fases iniciales del estudio.

\section{Técnica quirúrgica: GRUPO B}

Los 10 pacientes del grupo B, con 12 recesiones en total, fueron tratados con técnicas de RHG. Se utilizaron membranas reabsorbibles (membranas de colágeno) en todos los casos.

Se insertó una pequeña cantidad de hidroxiapatita entre la superficie radicular y la membrana posicionada para cubrir por completo la recesión con el fin de mantener la membrana y evitar su colapso sobre la superficie radicular. Durante la cicatrización, la membrana constituye una barrera frente a la rápida proliferación apical del componente epitelial y mantiene un espacio real entre la superficie radicular y la membrana en sí, permitiendo así la lenta regeneración de las células derivadas del ligamento periodontal. ${ }^{3,20,21}$

Al final de la cirugía, todas las membranas se cubrie- 


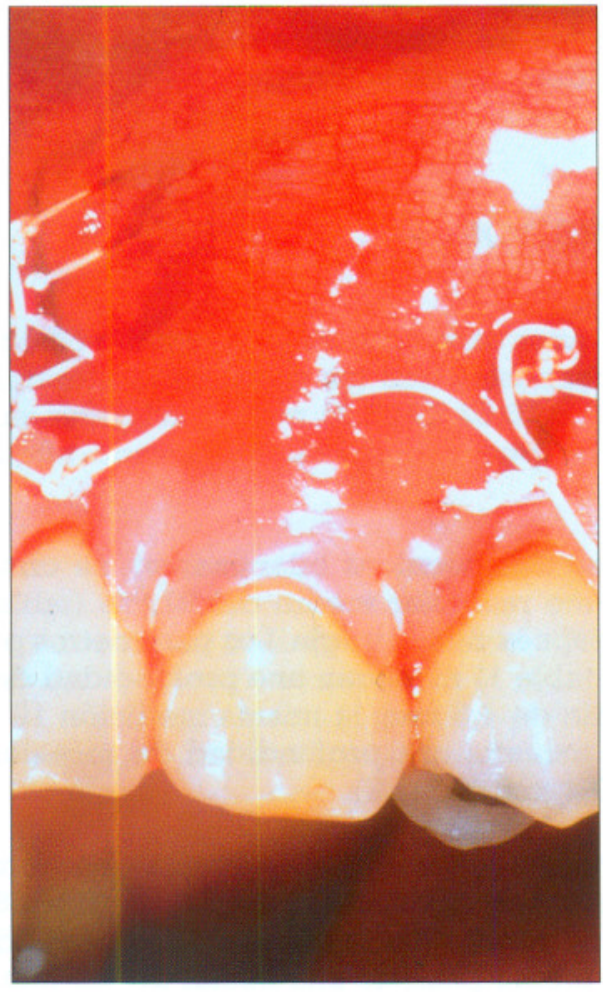

Fig. 10: Sutura del colgajo posicionado coronalmente.

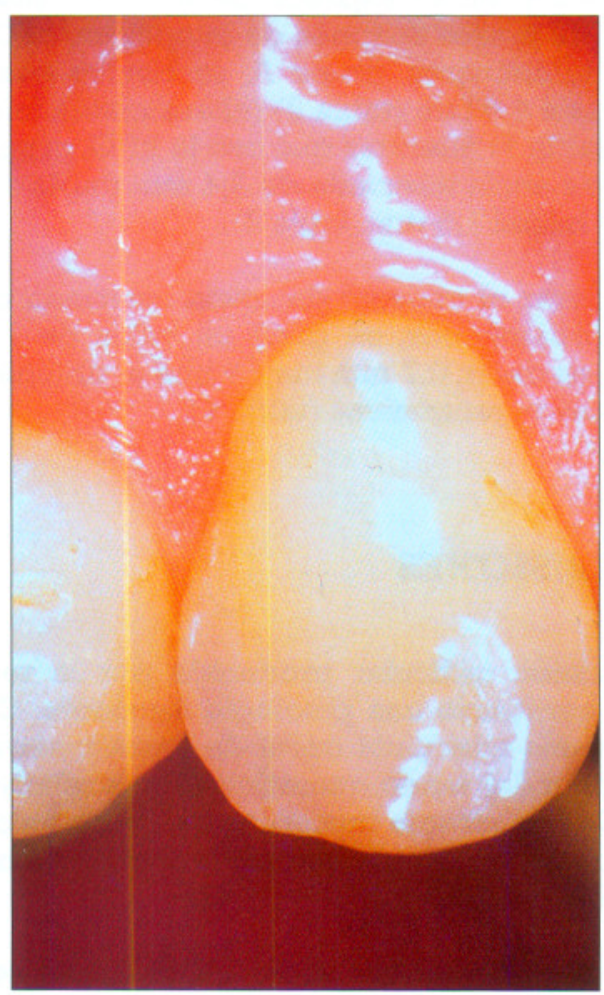

Fig. 11: Cicatrización.

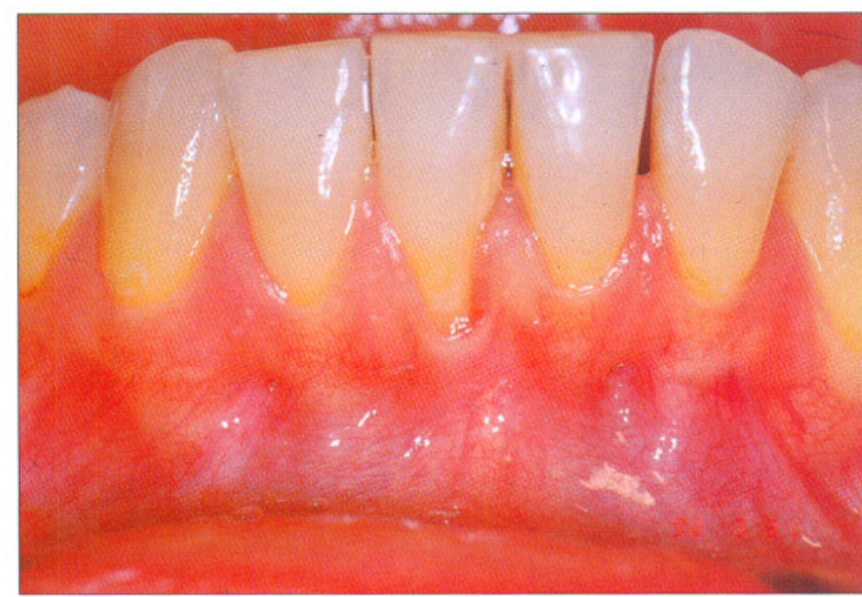

Fig. 12: Recesión gingival en 41, con pérdida del periodonto marginal en todos los dientes adyacentes (paciente número 4 del grupo $B$ ).

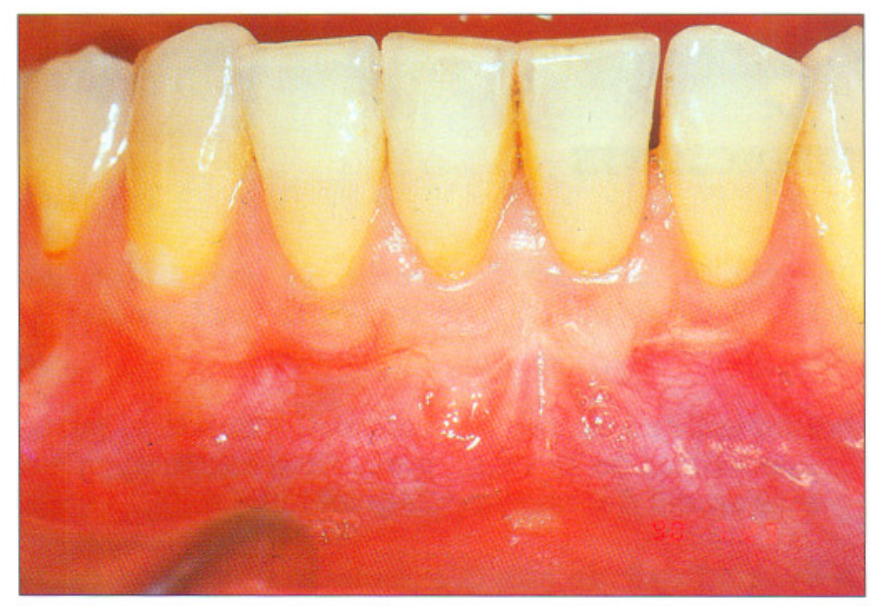

Fig. 13: Cicatrización a lols 4 meses: obsérvese como el periodonto marginal es menos espeso que el paciente tratado con injerto bilaminar.

ron con colgajos posicionados coronalmente, sin que se produjeran exposiciones de membrana (fig. 1213).

Postoperatoriamente, se colocó gel de clorexidina sobre las áreas tratadas sin ningún apósito periodontal. Los pacientes fueron invitados a no cepillarse las áreas quirúrgicas, enjuagándose con clorexidina al $0,2 \%$ para su higiene oral.

Las citas de control fueron a los 3-7-15 y 30 días después de la operación para verificar el proceso de cicatrización y la posible exposición de las membranas; en el período de 7-10 días se eliminaron los puntos. Los pacientes reanudaron sus medidas de control de placa, cepillando delicadamente las áreas tratadas a los 30 días de la cirugía. 


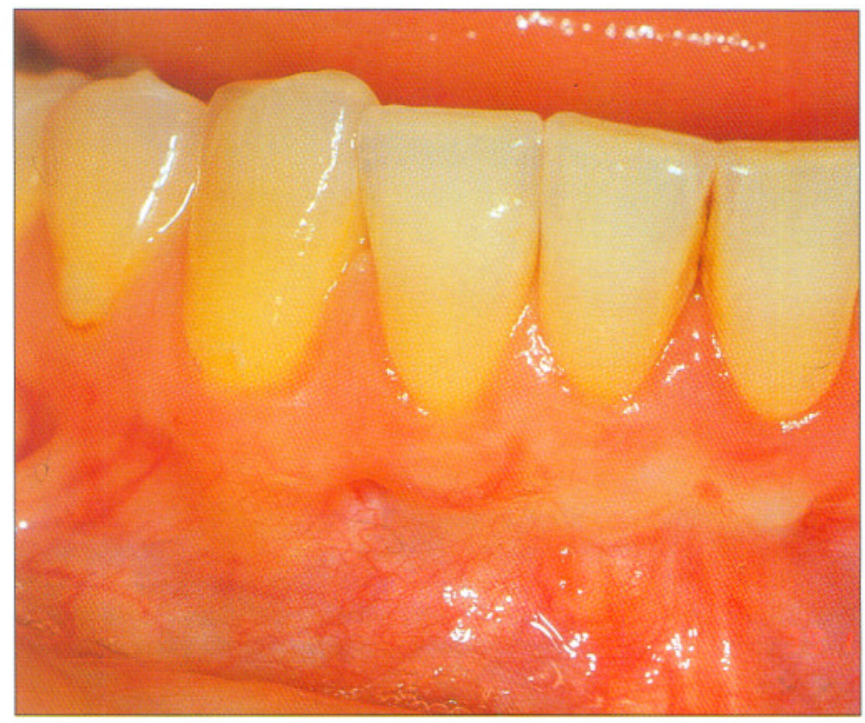

Fig. 14: Rece

\section{MEDICIONES}

Durante la fase preoperatoria, se registraron los siguientes parámetros en cada paciente (tablas 1, 2):

Profundidad de recesión-medición desde el punto más apical de la unión cemento-esmalte al punto más apical del margen gingival libre.

Profundidad de sondaje tomada a lo largo de la línea media de la superficie expuesta.

Altura de la encía insertada, que se calculó restando la profundidad de surco gingival (profundidad de sondaje) desde la distancia entre el margen gingival libre y la línea mucogingival.

Durante la fase intraoperatoria, el nivel del margen óseo (tablas 1, 2) se registró midiendo la distancia entre el punto más apical de la unión cemento-esmalte y el punto más apical del margen óseo. Durante la fase postoperatoria, se registraron los siguientes parámetros (tablas 3-4):

Profundidad de recesión, profundidad de sondaje, altura de la encía insertada, medidos a los 6 meses y a los 12 meses de la cirugía.

El espesor de la encía insertada 12 meses después de la cirugía se midió con una sonda periodontal, con anestesia local previa, $3 \mathrm{~mm}$ desde el margen gingival libre.
Porcentaje de cubrimiento radicular, calculado 12 meses después de la cirugía.

\section{RESULTADOS}

Los resultados obtenidos en este estudio clínico, aunque no contrastan con los datos de la literatura más reciente,6,9,16,22,23,25,31 muestran ligeras variaciones que se pueden imputar al limitado número de pacientes.

En el grupo $\mathbf{A}$ (técnicas bilaminares), se obtuvo un cubrimiento radicular medio del 91,9\% (tabla 5) 12 meses después de la cirugía. Los parámetros preoperatorios (tabla 1) muestran una profundidad de recesión media de 4,5 mm; la misma medición 12 meses después muestra una profundidad de recesión residual de 0,4 mm (tabla 3 ).

En el grupo B (técnica regenerativa), se obtuvo un cubrimiento radicular medio del $77,3 \%$ (tabla 6) a los 12 meses después de la cirugía. La profundidad de recesión media pasa de una inicial de $4,8 \mathrm{~mm}$ (tabla 2) a una residual de $1,1 \mathrm{~mm}$ a los 12 meses (tabla 4).

Las mayores diferencias entre grupos se producen en la cantidad y en el espesor de la encía insertada obtenida 12 meses después de la operación. Con las técnicas bilaminares, grupo $A$, se obtuvo una encía insertada de 4,9 mm (tabla 3) (altura media inicial de 1,5 mm, tabla 1) mientras que con la RHG, grupo B, se obtuvo una encía insertada de $3,4 \mathrm{~mm}$ (tabla 4) (altura media inicial 1,9 mm, tabla 2 ).

Al considerar el espesor de encía insertada con las técnicas bilaminares, se ganó un valor de 1,9 mm (tabla 3), es decir, 0,7 mm mayor que el obtenido con las técnicas regenerativas (tabla 4).

\section{CONCLUSIONES}

La exposición radicular producida por la recesión gingival constituye una patología frecuente. Cuando no existe una adecuada cuota de encía insertada, la restauración del tejido queratinizado es relativamente sencilla con cirugía mucogingival, pero en ocasiones el cubrimiento radicular puede suponer un problema difícil.

Entre las técnicas que se sugieren, el injerto conectivo bilaminar supone una lección terapéutica válida debido a sus ventajas: 
buena predicibilidad del resultado

> posibilidad de aumentar el espesor de la encía insertada

buen resultado estético, aunque a veces sea necesaria cirugía plástica correctora tras la cicatrización

operaciones en un único tiempo, aunque estén afectadas dos zonas

numerosas variaciones quirúrgicas, que garantizan una amplia versatilidad en su aplicación.

La RHG es considerada como una alternativa a las técnicas bilaminares, dado que tras los excelentes resultados en la regeneración del periodonto profundo, se ha aplicado con éxito para regenerar el periodonto superficial.

Aunque esta técnica tenga una experimentación clínica más reciente, requiere un protocolo quirúrgico exacto y un preciso seguimiento, no se puede realizar para tratar las recesiones múltiples y adyacentes, y su costo es elevado.

De ahí que las técnicas bilaminares constituyan una cirugía sencilla, caracterizada por una excelente predicibilidad del resultado del cubrimiento radicular, incluso en relación con las técnicas regenerativas.

Al considerar los datos de este estudio clínico con la literatura internacional, se puede afirmar que el injerto de tejido conectivo constituye una alternativa válida a la RHG para tratar las recesiones gingivales. De hecho, con las técnicas bilaminares se obtiene un mayor incremento en la cantidad y el espesor de la encía insertada, permitiendo tratar múltiples recesiones adyacentes y garantizar una elevada predicibilidad en el cubrimiento radicular.

\section{BIBLIOGRAFÍA}

1. CASSESE M., TORTORA P., MARASCA F., CARRESE C. Casi clinici di recessioni gengivali.Il dentista moderno 4:481-486,1995.

2. DE TREY E., BERNIMOULIN J.P. Influence of free gingival graft on the health of the marginal gingiva. J. Clin. Period. 7:381-393,1980.

3. DE SANCTIS M., ZUCCHELLI G. Atlante di chirurgia estetica mucogengivale. Edizioni Martina Bologna.

4. DORFMAN H.S., KENNEDI J.E., BIRD W.C. Longitudinal evaluation of free autogenous gingival grafts. J. Clin. Period. 7:316-324, 1980.
5. FELICORI L. Gli innesti bilaminari nelle esposizioni radicolari. Dental Cadmos 13:13-46,1994.

6. HARRIS R.J. The connective tissue and partial thickness double pedicle graft: a predictable method of obtaining root coverage. J. Period. 63:477-486,1992.

7. HARRIS R.J. The connective tissue with partial thickness double pedicle graft: the results of 100 consecutivelytreated defects. J. Period. 65:448-461,1994.

8. KHOCHT A., SIMON G., PERSON P., DENEPITIYA J.L. Gingival recession in relation to history of hard toothbrush use. J. Period. 64: 900-905,1993.

9. LANGER B., LANGER L. Subepithelial connective tissue graft technique for root coverage. J. Period. 56:715720,1985 .

10. LINDHE J., NYMAN S. Alterations of the position of the marginal soft tissue following periodontal surgery. J. Clin. Period. 7:525-530,1980.

11. LINDHE J. Parodontologia. Edi-ermes Milano,1991.

12. LÖST C. Depth of alveolar bone dehiscences in relation of gingival recessions. J. Clin. Period. 11:583-589,1984.

13. MAYNARD J.G. The rationale for mucogingival therapy in the child and adolescent. Int. J. Period. Rest. Dent. $1: 37-50,1987$.

14. MILLER P.D. Root coverage with the free gingival graft. J. Period. 58:674-681,1987.

15. MILLER P.D. Root coverage grafting for regeneration and aesthetics. Period. 2000. 1:118-127,1993.

16. NELSON S.W. The subpedicle connective tissue graft. J. Period. 58:95-102,1987.

17. NEVINS M. Attached gingiva - mucogingival therapy and restorative dentistry. Int. J. Period. Rest. Dent. 4:925,1986 .

18. PARMA-BENFENATI S., FUGAZZOTTO P.A., RUBEN M.P. The effect of restorative margins on the postsurgical development and nature of the periodontium. Part I. Int. J. Period. Rest. Dent. 6:31-51,1985.

19. PARMA-BENFENATI S., FUGAZZOTTO P.A., FERREIRA P.M., RUBEN M.P., KRAMER G.M. The effect of restorative margins on the postsurgical development and nature of the periodontium. Part II. Int. J. Period. Rest. Dent. 1:65-75,1986.

20. PINI PRATO G., TINTI C., VINCENZI G., MAGNANI C., CORTELLINI P., CLAUSER C. Guided tissue regeneration versus mucogingival surgery in the treatment of human buccal gingival recession. J. Period. 63:919928,1992 .

21. PINI PRATO G., CLAUSER C., CORTELUINI P. Guided tissue regeneration and a free gingival graft for the management of buccal recession. Int. J. Period. Rest. Dent. 13:487-493,1993. 
22. PINI PRATO G., CLAUSER C., CORTELUINI P., TINTI C., VINCENZI G., PAGLIARO U. Guided tissue regeneration versus mucogingival surgery in the treatment of Human buccal recession. A 4-year follow-up study. J. Period. 67:1216-1223,1996.

23. RAETZKE P.B. Covering localized areas of root exposure employing the "envelope" technique. J. Period. 7:397-402,1985.

24. SMITH R.G. Gingival recession. J. Clin. Period. 24:201205, 1997.

25. TINTI C., VINCENZI G., PINI PRATO G.P. Guided tissue regeneration in human facial recession. A 12 case report. J. Period. 63(6):554,1992.

26. TOLMIE P.N., RUBINS R.P., BUCK G.S., VAGIANOS V., LANZ J.C. Prevedibilità sulla copertura delle radici mediante autotrapianti liberi gengivali e applicazione di acido citrico. Int. J. Period. Rest. Dent. 11:261271,1991 .
27. URBANI G., LOMBARDO G., CAVALLERI G., DE LUCA M. Le recessioni gengivali. Il Dentista Moderno, I Dossier 3,1993 .

28. WENNSTRÖM J.L. Lack of association between width of attached gingiva and development of soft tissue recession. J. Clin. Period. 14:181-184,1987.

29. WENNSTRÖM J.L.,ZUCCHELLI G. Increased gingival dimensions. A significant factor for successful outcome of root coverage procedures? J. Clin. Period. 23:770777,1996 .

30. WENNSTRÖM J.L. Mucogingival therapy. Ann. Period. 1:671-701,1996.

31. ZUCCHELUI G., CLAUSER C., DE SANCTIS M., CALANDRIELLO M. Mucogingival versus guided tissue regeneration procedures in the treatment of deep recession type defects. J. Period. 69(2):138-145, 1998. 